\title{
Flow characteristics of liquids in microtubes driven by a high pressure
}

\author{
Hai-hang Cui and Zhan-hua Silber-Li \\ State Key Laboratory of Nonlinear Mechanics, Institute of Mechanics, CAS, Beijing, 100080, China \\ Shan-nong Zhu \\ Laboratory of Polymer Physics and Chemistry, Institute of Chemistry, CAS, Beijing, 100080, China
}

(Received 23 January 2003; accepted 9 February 2004; published online 8 April 2004)

\begin{abstract}
The flow characteristics of liquids in microtubes driven by a high pressure ranging from $1 \mathrm{MPa}$ to $30 \mathrm{MPa}$ are studied in this paper. The diameter of the microtube is from $3 \mu \mathrm{m}$ to $10 \mu \mathrm{m}$ and liquids composed of simple small molecules are chosen as the working fluids. The Reynolds number ranges from 0.1 to 24 . The behavior of isopropanol and carbon tetrachloride under high pressure is found different from the prediction from conventional Hagen-Poiseuille (HP) equation. The normalized friction coefficient $C^{*}$ increases significantly with the pressure. From an analysis of the microtube deformation, liquid compressibility, viscous heating and wall slip, it may be seen that the viscosity at high pressure plays an important role here. An exponential function of viscosity vs pressure is introduced into the HP equation to counteract the difference between experimental and theoretical values. However, this difference is not so marked for di-water. (c) 2004 American Institute of Physics. [DOI: 10.1063/1.1691457]
\end{abstract}

\section{INTRODUCTION}

The characteristics of liquid flow in a microchannel is important in the design of microfluidic MEMS. ${ }^{1}$ It has been established for gaseous flow that the pressure distribution along the channel becomes nonlinear when the cross section of the channel is sufficiently small. This is because a transition from continuum flow to free molecules flow takes place when the Knudsen number increases. ${ }^{2}$ For the liquid flow in a microscale channel, several typical experiments have been reported recently, however, the results are not always consistent. ${ }^{3-8}$ Pfahler et al. ${ }^{7}$ measured the friction factor of isopropanol in a microchannel $(100 \mu \mathrm{m}$ in width, less than $40 \mu \mathrm{m}$ in depth and with a hydraulic diameter of $39.7 \mu \mathrm{m}$ ), and found that the apparent viscosity became smaller than that in the macroscale. On the other hand, in Papautsky's ${ }^{8}$ experiments with water (Reynolds number $=0.001-18$ and hydraulic diameter $=57 \mu \mathrm{m}$ ), it was found that the experimental flow rate was smaller than the value predicted by the classical theory by a factor of 1.2. Recently, Sharp et al. ${ }^{9}$ carried out systematic experiments for water and isopropanol in microtubes (Reynolds number $=50-1500$ and hydraulic diameter $=75 \mu \mathrm{m}-242 \mu \mathrm{m}$ ), whose results were in good agreement with the classical theory. For smaller Reynolds number, Li et al. ${ }^{10,11}$ carried out experiments in a microtube with a diameter of about $20 \mu \mathrm{m}$ using liquids consisting of simple small molecules. Their results showed that the macroscopic theory is adequate enough for polar or nonpolar liquids and di-water. These recent results ${ }^{9-11}$ all indicate that the behaviors of liquid flows in microchannels of larger than $20 \mu \mathrm{m}$ in diameter are in good agreement with the continuum theory. But the conflicting results about the flow in microtubes of smaller diameter remain to be studied.

Experimental results of liquid flow in the 3-10 $\mu \mathrm{m}$ microtubes are presented here. We focus on liquids made of small molecules, such as the di-water, isopropanol and carbon tetrachloride. Because the flow rate is proportional to the fourth power of the diameter, a pressure up to 1-30 MPa must be maintained to provide a flow rate that can be accurately measured. The experimental setup and method are described in Sec. II and the results are given in Sec. III. The analysis about the microtube deformation, the liquid compressibility, the wall slip and the viscosity caused by high pressure is presented and then a revised equation is introduced in Sec. IV. Finally, conclusions are made in Sec. V.

\section{EXPERIMENTAL SETUP AND METHODS}

\section{A. Theory of laminar flow in a tube}

In the case of steady laminar flow in a straight tube, the Navier-Stokes (NS) equation can be simplified as HagenPoiseuille (HP) equation. The flow rate $Q_{\mathrm{HP}}$ can be expressed as

$$
Q_{\mathrm{HP}}=\frac{\pi d^{4}}{128 \mu_{0} L} P,
$$

where $d$ and $L$ are the diameter and the length of the microtube, respectively, $P$ is the pressure drop between the two ends of the tube, and $\mu_{0}$ the viscosity. Reynolds number Re and the normalized friction coefficient $C^{*}$ are defined as

$$
\begin{aligned}
& \operatorname{Re}=\rho U d / \mu_{0}, \\
& f=P /\left(\frac{\rho U^{2}}{2} \frac{L}{d}\right), \\
& C^{*}=\frac{(\operatorname{Re} f)_{\exp }}{(\operatorname{Re} f)_{\mathrm{HP}}}=\frac{Q_{\mathrm{HP}}}{Q_{\exp }},
\end{aligned}
$$



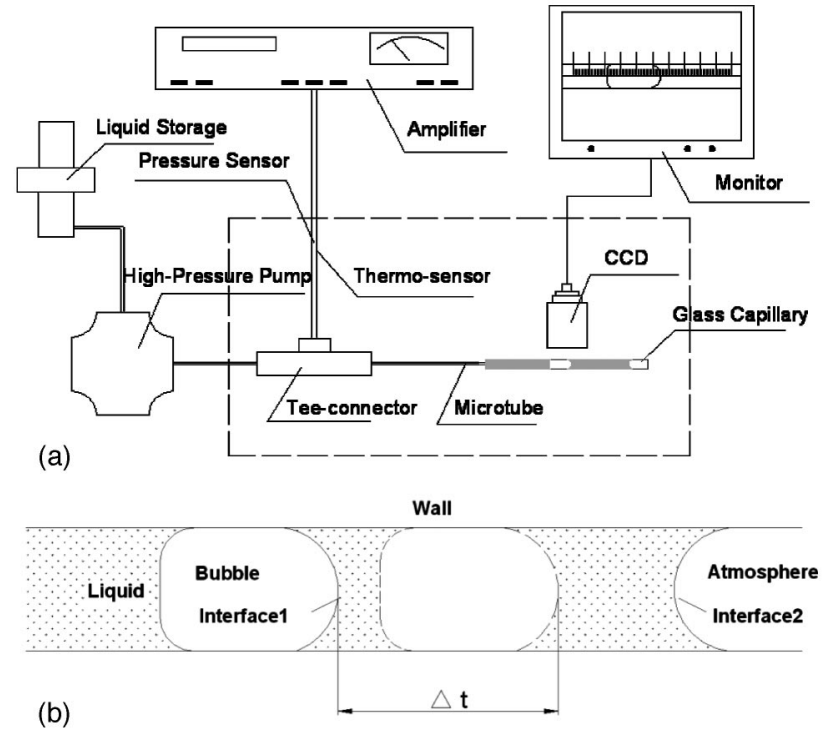

FIG. 1. A sketch of the high-pressure microflow setup (a) and the principle of flow rate measurement (b).

where $U$ is the average velocity in the tube, $\rho$ the density of the liquid, and $f$ the friction coefficient.

\section{B. Experimental setup}

Our experiment was carried out in a high-pressure microflow setup in LNM laboratory [Fig. 1(a)]. The experimental setup includes three units: the pressure source, the testing section and the flux measuring section. The high-pressure pump of $1-40 \mathrm{MPa}$ (147-5800 Psi) is used to drive the working liquids. A feedback circuit controls two pistons in the pump to keep the output of pressure steady. The testing section consists of a tee connector, a pressure transducer, a thermocouple, and a microtube. The pressure transducer and the thermocouple are connected to the tee connector, through which the inlet pressure of the microtube and the temperature of the working liquid can be measured. One end of the microtube is linked to the tee connector with a mechanical seal and the other end is inserted into a glass capillary with glues. The microtube is long enough to neglect the inlet and outlet effects. The working liquid passing through the microtube is gathered in the glass capillary. The surface of the liquid's column is denoted as interface 2 [Fig. 1(b)]. Considering the possibility of evaporation on interface 2 , even if it can be neglected, the interface 1 is used as the reference. At each measurement of the flow rate, a gas bubble is first injected in the capillary to form the interface 1 . Through measuring the displacement $s$ of the reference interface and the interval $t$, the flow rate $Q_{\exp }$ can be calculated by the following equation:

$$
Q_{\exp }=\frac{\pi D^{2} s}{4 t},
$$

where $D$ is the diameter of the capillary.



FIG. 2. The AFM image (top) and the distribution of roughness peak of the inner wall of microtube (bottom).

\section{Measurement of roughness}

In order to measure the roughness, the microtube must be cut along the axis with its inner surface exposed. In preparing the sample, the microtube is embedded in an opaque mounting material by a metallurgical specimen mounting mould, and then the sample is ground, polished, and washed. The probe of Atomic Force Microscope (Auto Probe CT Research Scanning Probe Microscope) moves continuously over an area of $12 \mu \mathrm{m}^{2}$ at each spot to measure the profile of roughness peak (Fig. 2). The relative roughness $R a$ is defined as

$$
R a=\frac{\Delta h}{R} \times 100 \%,
$$

where $\Delta h$ is the average height of the roughness peak and $R$ is the radius of the microtube.

Two kinds of microtubes, $10 \mu \mathrm{m}$ and $500 \mu \mathrm{m}$, made by the same company with the same material are used in the measurement. For the roughness measurement, the microtube must be ground and polished. After this process, the microtube of $10 \mu \mathrm{m}$ is much more difficult to clean than that of $500 \mu \mathrm{m}$. So the average height $\Delta h$ of the former is measured to be about $70 \mathrm{~nm}$, much greater than that of the latter, that is, $7.12 \mathrm{~nm}$. But, even with the value of $70 \mathrm{~nm}$, the relative surface roughness is calculated to be less than $0.7 \%$. So the microtube can be regarded as the hydraulic smooth tube.

\section{Working liquids}

Some simple liquids with small molecules such as isopropanol, carbon tetrachloride and di-water are used in our experiments. They have different molecular structures: diwater has a very strong hydrogen bond; isopropanol is a polar liquid and carbon tetrachloride is a nonpolar liquid with a symmetric molecular structure. All of them can be treated as Newtonian liquid under the critical shear rate 
TABLE I. Uncertainties of the experimental system in measuring the normalized friction coefficient.

\begin{tabular}{ccccccccc}
\hline \hline $\begin{array}{c}\text { Microtube } \\
(\mu \mathrm{m})\end{array}$ & $d$ & $P$ & $\mu$ & $L$ & $D$ & $s$ & $t$ & $\begin{array}{c}\text { Uncertainty of } \\
\text { experimental } \\
\text { system }\end{array}$ \\
\cline { 2 - 7 } & & & & & & & & $\pm 4.5 \%$ \\
10.02 & $\pm 1 \%$ & & & & & & \\
4.99 & $\pm 2 \%$ & $\pm 0.3 \%$ & $\pm 0.75 \%$ & $\pm 0.2 \%$ & $\pm 0.5 \%$ & $\pm 1 \%$ & $\pm 0.2 \%$ & $\pm 8.3 \%$ \\
2.95 & $\pm 3.3 \%$ & & & & & & & $\pm 13.4 \%$ \\
\hline \hline
\end{tabular}

$O\left(10^{12}\right)$. It is assumed that the molecules of liquids are isolated and homogeneously distributed. The possible structure scale $\delta$ of the liquid is

$$
\delta=\sqrt[3]{\gamma / \rho \cdot N A}
$$

where $\gamma$ is the molecular weight, $\rho$ the density of the liquid, $N A$ Avogadro number. For the three working liquids, $\delta$ is less than $1 \mathrm{~nm}$, respectively. It is obvious that the molecule's scale is much smaller than the characteristic flow scale. The viscosity of the liquid is measured by Pinkevitch viscometer and the electrical conductivity of di-water is measured by DDS-12A electrical conductometer. The dissolved gas under a high-pressure condition may influence the flow. Therefore, we pour the pure nitrogen of very low solubility into working liquids to replace the gas, and then the liquids are completely de-gassed through the ultrasonic instrument.

\section{E. The uncertainty of experimental system}

Generally, the uncertainty $u$ of a function $f$ is related with the variables measured in the experiments. From Eqs. (1), (4), and (5), the uncertainty $u_{C^{*}}$ in $C^{*}$ is defined as

$$
\frac{u_{C *}}{C^{*}}= \pm \sqrt{\frac{16}{d^{2}} u_{d}^{2}+\frac{u_{P}^{2}}{P^{2}}+\frac{u_{\mu}^{2}}{\mu_{0}^{2}}+\frac{u_{L}^{2}}{L^{2}}+\frac{4}{D^{2}} u_{D}^{2}+\frac{u_{s}^{2}}{s^{2}}+\frac{u_{t}^{2}}{t^{2}}}
$$

where $u_{i}$ in the radical sign is the uncertainty of the related parameter referring to the respective subscripts. Because the flow rate is proportional to the fourth power of diameter, the uncertainty in the geometric measurement of a microtube becomes very important. Three microtubes of different nominal diameter, $8 \mu \mathrm{m}, 4 \mu \mathrm{m}$, and $2 \mu \mathrm{m}$ are provided by Polymicro Technologies Company with a quoted accuracy of $\pm 20 \%$ for their inner diameters. Scanning Electronic Microscopes (JSM-5600 LV and CSM950) are used in measuring the diameter with a precision of $0.1 \mu \mathrm{m}$ and several cross sections are chosen to verify the distribution of the diameter along the axis. The measured diameters are $10.02 \mu \mathrm{m}, 4.99$ $\mu \mathrm{m}$, and $2.95 \mu \mathrm{m}$ with uncertainties of $\pm 1 \%, \pm 2 \%$, and $\pm 3.3 \%$, respectively. Although, the diameter in axial length may be nonuniform, there is not sudden change. The uncertainties of other parameters are approximately constant

\begin{tabular}{|c|c|c|c|c|c|}
\hline Working liquids & $\begin{array}{l}\text { Diameter } \\
(\mu \mathrm{m})\end{array}$ & $\begin{array}{l}\text { Length } \\
(\mathrm{mm})\end{array}$ & $\begin{array}{c}\text { Temperature } \\
\left({ }^{\circ} \mathrm{C}\right)\end{array}$ & $\begin{array}{c}\text { Viscosity } \\
\text { (mPa s) }\end{array}$ & Re number \\
\hline \multirow[t]{9}{*}{ Di-water } & \multirow{4}{*}{10.02} & 57.43 & 26.4 & 0.862 & \multirow{4}{*}{$1.22-23.94$} \\
\hline & & 51.06 & 22.2 & 0.950 & \\
\hline & & 57.43 & 25.7 & 0.875 & \\
\hline & & 44.86 & 19.7 & 1.009 & \\
\hline & \multirow[t]{2}{*}{4.99} & 40.07 & 20.0 & 1.002 & \multirow[t]{2}{*}{$0.52-2.98$} \\
\hline & & 73.44 & 19.6 & 1.012 & \\
\hline & \multirow{3}{*}{2.95} & 47.42 & 18.8 & 1.034 & \multirow{3}{*}{$0.09-0.61$} \\
\hline & & 34.77 & 20.0 & 1.002 & \\
\hline & & 48.59 & 18.8 & 1.034 & \\
\hline \multirow[t]{7}{*}{ Isopropanol } & \multirow{3}{*}{10.02} & 49.33 & 21.5 & 2.299 & \multirow{3}{*}{$0.59-3.42$} \\
\hline & & 46.06 & 19.0 & 2.438 & \\
\hline & & 46.06 & 18.0 & 2.549 & \\
\hline & \multirow{2}{*}{4.99} & 55.02 & 19.7 & 2.424 & \multirow{2}{*}{$0.054-0.34$} \\
\hline & & 62.91 & 20.5 & 2.367 & \\
\hline & \multirow{2}{*}{2.95} & 49.02 & 18.3 & 2.527 & \multirow{2}{*}{$0.022-0.13$} \\
\hline & & 28.73 & 23.3 & 2.181 & \\
\hline \multirow[t]{7}{*}{ Carbon tetrachloride } & \multirow{2}{*}{10.02} & 48.81 & 19.9 & 1.064 & \multirow{2}{*}{$0.67-13.31$} \\
\hline & & 53.29 & 22.0 & 1.025 & \\
\hline & \multirow{2}{*}{4.99} & 41.35 & 19.0 & 1.078 & \multirow{2}{*}{$0.50-2.67$} \\
\hline & & 35.84 & 22.0 & 1.025 & \\
\hline & \multirow{2}{*}{2.95} & 31.99 & 24.7 & 0.987 & \multirow{3}{*}{$0.11-0.64$} \\
\hline & & 37.16 & 21.7 & 1.030 & \\
\hline & 2.97 & 49.54 & 19.0 & 1.078 & \\
\hline
\end{tabular}

TABLE II. Experimental parameters. 




FIG. 3. The flow rate as a function of $P / \mu_{0} L$ for three liquids in $10 \mu \mathrm{m}$ microtube: water $(\square)$, isopropanol $(\bigcirc), \mathrm{CCL}_{4}(\triangle)$ and the range of theoretical flow rate due to the uncertainty (between two dotted lines).

in each experiment. The experimental uncertainties and parameters are listed in Table I and Table II, respectively.

\section{EXPERIMENTAL RESULTS}

The experimental results are presented as the arithmetic average values with the experimental uncertainty. The arithmetic average value is calculated from at least three measurements and the maximum standard deviation is less than $\pm 2.3 \%$. The experimental uncertainty contains two parts: the uncertainty of the experimental system (Sec. IIE) and a product of the standard deviation and $\zeta$, where $\zeta$ is a coefficient related to the number of measurements $N(3 \leqslant N \leqslant 5$, $\zeta=1.2-2.5, N>5, \zeta=1)$. Total uncertainties for three microtubes are $\pm 4.8 \%, \pm 8.6 \%$, and $\pm 13.6 \%$, respectively.

\section{A. Results for $10 \mu \mathrm{m}$ microtube}

The relationships of the flow rate $Q_{\exp }$ vs the pressure parameter $P / \mu_{0} L$ for three liquids are shown in Fig. 3. The

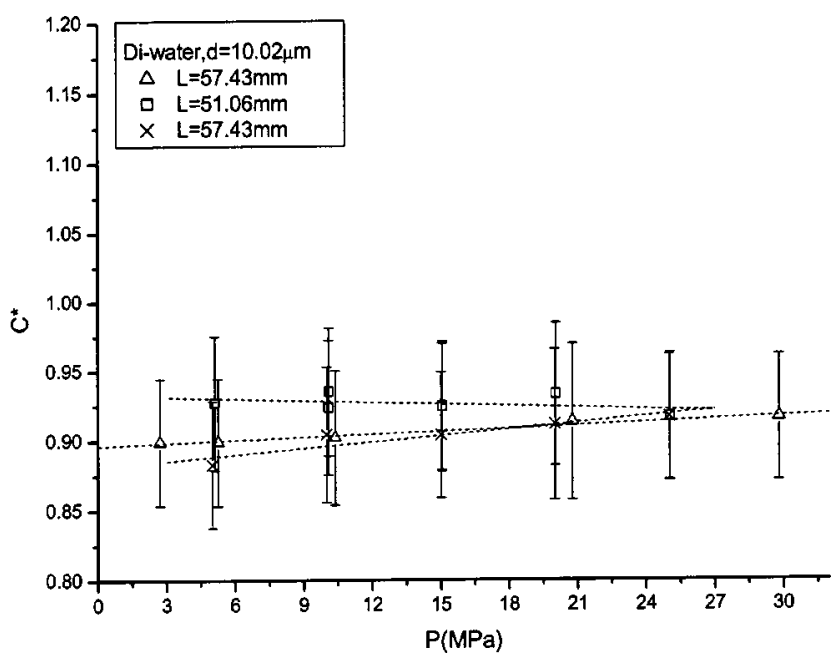

FIG. 4. The normalized friction coefficient vs pressure for water in $10 \mu \mathrm{m}$ microtube.

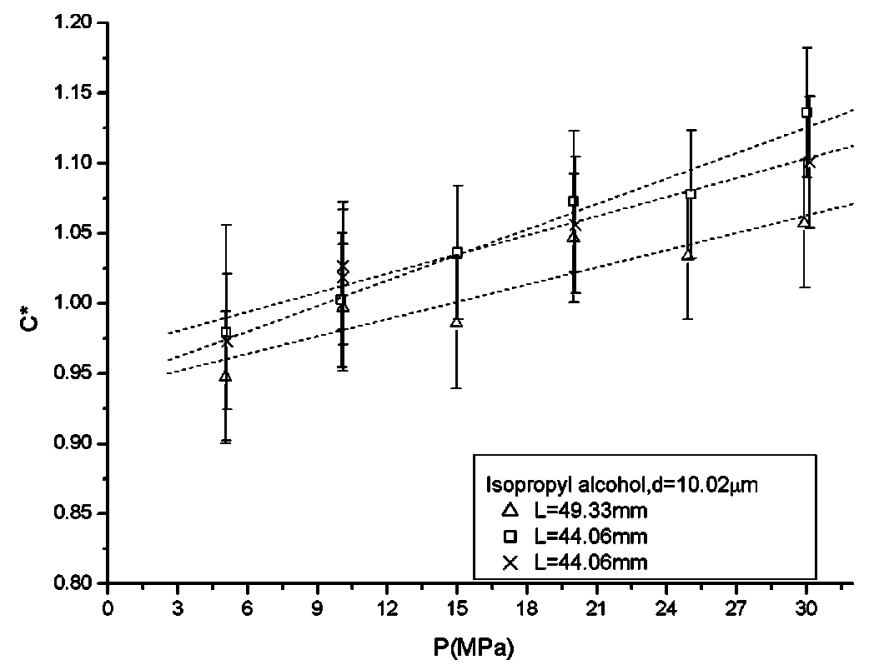

FIG. 5. The normalized friction coefficient vs pressure for isopropanol in 10 $\mu \mathrm{m}$ microtube.

relative uncertainty of $Q_{\mathrm{HP}}$ is $\pm 4.1 \%$ noted between two dotted lines, and that of $Q_{\exp }$ is $\pm 2.1 \%$, which is not noted for clearness. It obviously shows the absolute deviation between the experimental flow rate and the theoretical values, especially under a high pressure. For water, $Q_{\exp }$ is larger than $Q_{\mathrm{HP}}$, but for the other liquids, $Q_{\exp }$ is smaller than $Q_{\mathrm{HP}}$.

From the relationships of normalized friction coefficient $C^{*}$ vs the pressure (Figs. 4-6), the relative deviations are given for each liquid, respectively. $C^{*}$ varies slightly with the pressure for di-water (Fig. 4). But for the other two liquids, isopropanol and carbon tetrachloride, $C^{*}$ increases obviously with the pressure (Figs. 5 and 6). Even though the uncertainty is considered, there is still about $3-5 \%$ difference between the theoretical prediction and experimental results at the pressure of $30 \mathrm{MPa}$. For water, $C^{*}$ is smaller than 1. However, for other two liquids, $C^{*}$ is larger than 1 for most points except at lower pressure $(P<10 \mathrm{MPa})$.

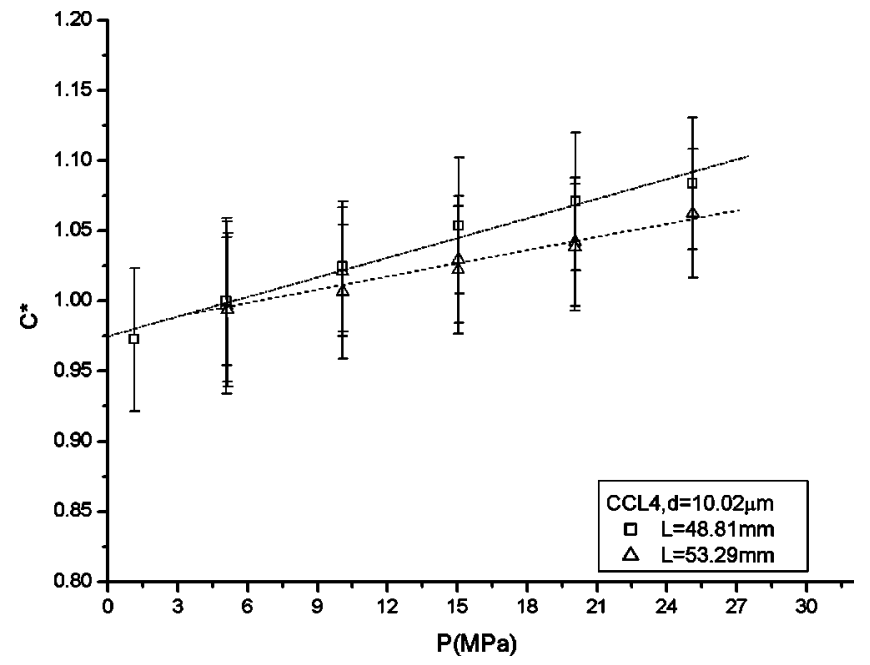

FIG. 6. The normalized friction coefficient vs pressure for carbon tetrachloride in $10 \mu \mathrm{m}$ microtube. 

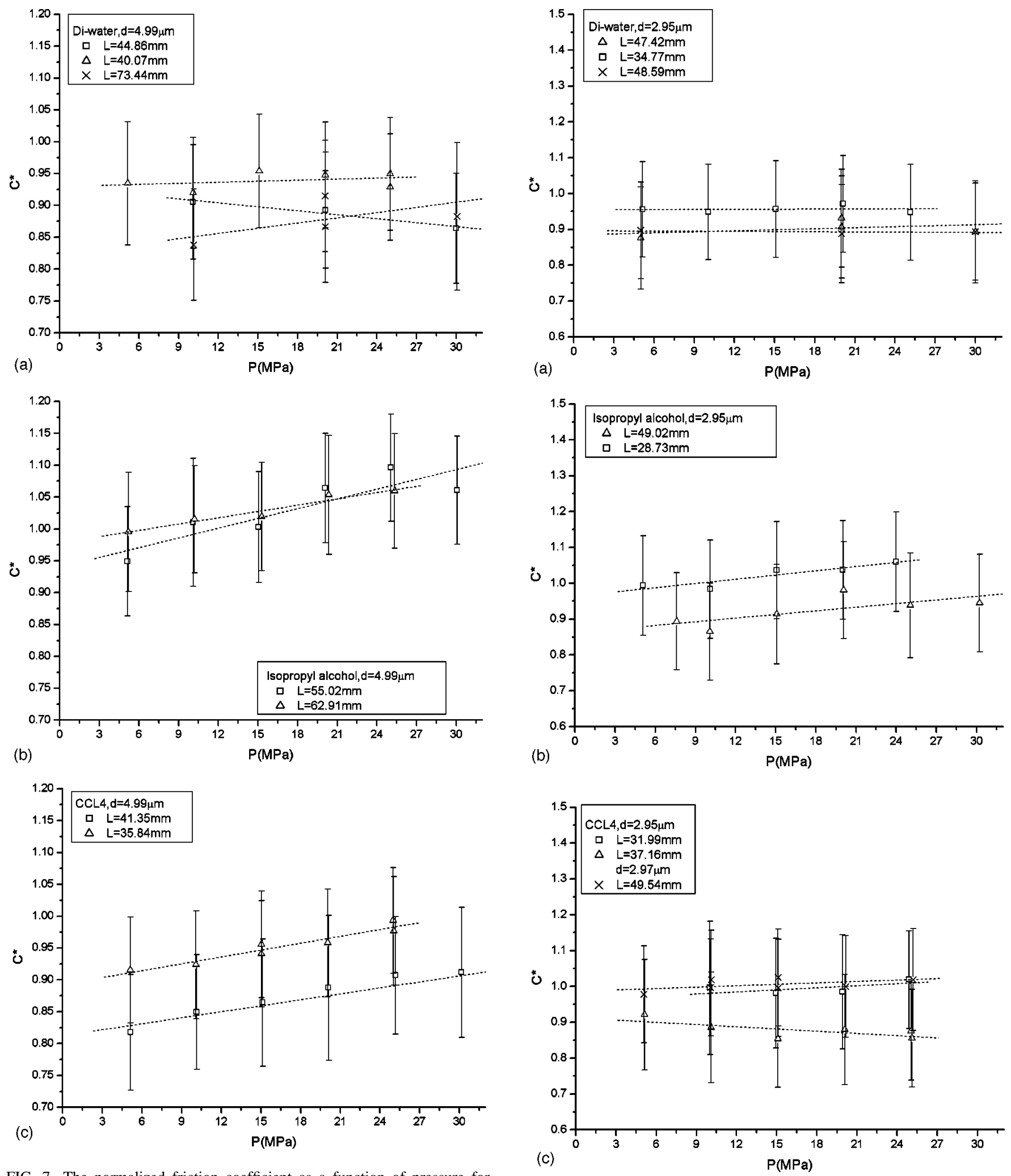

FIG. 7. The normalized friction coefficient as a function of pressure for three liquids in $5 \mu \mathrm{m}$ microtubes.

\section{B. Results for 3-5 $\mu \mathrm{m}$ microtubes}

The experimental results about $C^{*}$ vs the pressure for 5 $\mu \mathrm{m}$ and $3 \mu \mathrm{m}$ microtube are presented in Figs. 7 and 8. For water, $C^{*}$ varies slightly with the pressure $[$ Fig. $7(\mathrm{a})]$ and keeps nearly constant in the case of $3 \mu \mathrm{m}$ micotube [Fig. 8(a)]. For isopropanol and carbon tetrachloride [Figs. 7(b),

7(c), and 8(b)], $C^{*}$ increases with the pressure with a same tendency as in the case of $10 \mu \mathrm{m}$ tubes. For carbon tetrachloride in $3 \mu \mathrm{m}$ microtube [Fig. 8(c)], the tendency can also be seen even though the data of one test is scattered. 


\section{ANALYSES AND DISCUSSIONS}

There are several factors that may influence the experimental data with respect to the pressure drop: the deformation of the microtube, the compressibility of the liquids, the wall slip and the viscosity. They will be discussed in detail in the following.

\section{A. Effects of deformation and compressibility}

The microtube is treated as a thick wall cylinder and its radial expansion $y(r)$ of microtube can be calculated as ${ }^{12}$

$$
y(r)=\frac{d^{2} P}{E\left(d_{\text {outer }}^{2}-d^{2}\right)}\left[\frac{(1+\nu) d_{\text {outer }}^{2}}{r}+(1-\nu) r\right],
$$

where $d_{\text {outer }}$ is the outer diameter of the microtube, $E$ the Young's modulus of the glass $\left(6.2 \times 10^{11} \mathrm{dyn} / \mathrm{cm}^{2}\right), \nu$ Poisson ratio $(0.24) .{ }^{13}$ In the case of $10 \mu \mathrm{m}$ microtube with the maximum pressure of $30 \mathrm{MPa}$, the radical expansion is $6 \mathrm{~nm}$ and the relative change of the diameter is only $0.06 \%$. Therefore, the influence of the deformation on the flow rate can be neglected.

It is well known that liquids can be compressed under a high pressure and Mach number may be served as a scale of the compressibility. According to the relation of Mach number and the density of the liquids, we have

$$
\frac{\Delta \rho}{\rho}=2 M^{2} .
$$

In the case of the maximum pressure of $30 \mathrm{MPa}$, the maximum velocity of the liquid in $10 \mu \mathrm{m}$ microtube is $2 \mathrm{~m} / \mathrm{s}$ and the Mach number is near $2 \times 10^{-3}$. Therefore we can obtain the relative change of the density, $\Delta \rho / \rho_{0}<0.001 \%$, which can be neglected too.

\section{B. Effect of wall slip}

As the characteristic scale of the flow goes down to the micron/nanometer, the interaction between fluid and solid surfaces becomes more and more important. In the present experiment, there is a kind of microflow with the high shear rate $O\left(10^{6}\right)$ in the microtube with the hydrophilic wall. Based on the similar experimental condition, Choi ${ }^{14}$ proposed a formula that is a function of shear rate $\dot{\gamma}$ to calculate the slip length $\delta$ and slip velocity $u_{\text {slip }}$,

$$
\begin{aligned}
& \delta=0.059 \times \gamma^{0.485}, \\
& u_{\text {slip }}=\delta \cdot \dot{\gamma}_{\text {wall }}=\delta \cdot \frac{P \cdot d}{4 \mu_{0} L},
\end{aligned}
$$

here the parameters are the same as noted in the formula (1). Note that the unit of slip length in the above equation is nanometer. Considering the effect of slip, a revised theoretical flow rate is obtained as

$$
Q_{\mathrm{HP}-\mathrm{slip}}=u_{\text {slip }} \frac{\pi d^{2}}{4}+\frac{\pi d^{4}}{128 \mu_{0} L} P .
$$

The relative change of flow rate is defined as

$$
\begin{aligned}
& \frac{Q_{\mathrm{HP}-\mathrm{slip}}}{Q_{\mathrm{HP}}}=1+\frac{8 \delta}{d}=1+\frac{0.472 \times\left(\frac{P \cdot d}{4 \mu_{0} L}\right)^{0.485} \times 10^{-9}}{d}, \\
& C_{\mathrm{HP}-\text { slip }}^{*}=\frac{Q_{\mathrm{HP}-\mathrm{slip}}}{Q_{\exp }}=\left(1+\frac{8 \delta}{d}\right) C^{*} .
\end{aligned}
$$

In the case of the maximum pressure of $30 \mathrm{MPa}$, the wall slip results in about $5 \%$ increase of the flow rate in $10 \mu \mathrm{m} \mathrm{mi-}$ crotube. However, the effect of the wall slip is not sufficient to explain the decrease of flow rate of isopropanol and carbon tetrachloride.

\section{Effect of viscosity}

The viscosity is extremely sensitive to the temperature. In the case of a steady flow, the order of magnitude of the mechanical energy loss rate per unit volume due to viscous effects $\mu \dot{\gamma}^{2}$ is equal to that of the internal energy change rate due to heat conduction $\kappa \Delta T / R^{2}$ according to the energy equation, ${ }^{15}$ where $\dot{\gamma}$ and $R$ are the typical values of the shear rate and the system size, respectively, $T$ is the temperature and $k$ is the thermal conductivity of the fluid. It is then straightforward to obtain the order of magnitude for the relative change of viscosity due to viscous heating,

$$
\frac{\mu}{\mu_{0}} \approx \frac{\beta}{T_{0}} \frac{\mu}{\kappa}(R \gamma)^{2} \sim O\left(10^{-5}\right),
$$

where $\beta$ is the property coefficient. Therefore the viscous heating can be neglected.

Bridgman ${ }^{16}$ carried out systematic experiments to study the relationship of viscosity versus pressure. He pointed out that the viscosity of liquids, except the water, augmented with the increase of pressure. The relationship can be expressed approximately by an exponential function,

$$
\mu_{\text {app }}=\mu_{0} e^{\alpha P},
$$

where $\mu_{0}$ is the viscosity under the atmospheric temperature, $\mu_{\text {app }}$ the apparent viscosity and $\alpha$ is the property coefficient. The variation of pressure drop $d P$ along $d x$ is

$$
d P=\frac{128 \mu_{\mathrm{app}} Q}{\pi d^{4}} d x .
$$

Applying Eq. (17), integrating Eq. (18) along $L$ and considering the pressure condition between two ends of the microtube, the ratio of the revised flow rate $Q_{\mathrm{HP}-p \mu}$ to the flow rate $Q_{\mathrm{HP}}$ is

$$
\frac{Q_{\mathrm{HP}-p \mu}}{Q_{\mathrm{HP}}} \approx\left(1-\frac{\alpha P}{2}\right) .
$$

The revised normalized friction coefficient becomes

$$
C_{\mathrm{HP}-p \mu}^{*}=\frac{Q_{\mathrm{HP}-P \mu}}{Q_{\exp }}=\left(1-\frac{\alpha P}{2}\right) C^{*} .
$$

The property coefficient, $\alpha$, can be calculated from the data of the relative viscosity given by Bridgman ${ }^{16}$ in Table III. For isopropanol and carbon tetrachloride, $\alpha$ are 7.90 $\times 10^{-3} \mathrm{MPa}^{-1}$ and $8.08 \times 10^{-3} \mathrm{MPa}^{-1}$, respectively. Based 
TABLE III. Relative viscosity for different liquids in Bridgeman (Ref. 16).

\begin{tabular}{|c|c|c|c|c|c|c|c|}
\hline & \multirow{2}{*}{$\begin{array}{c}\text { Pressure } \\
(\mathrm{MPa})\end{array}$} & \multicolumn{3}{|c|}{ Relative viscosity } & \multicolumn{3}{|c|}{$\alpha\left(\mathrm{MPa}^{-1}\right)$} \\
\hline & & $0\left({ }^{\circ} \mathrm{C}\right)$ & $10.3\left({ }^{\circ} \mathrm{C}\right)$ & $30\left({ }^{\circ} \mathrm{C}\right)$ & $0\left({ }^{\circ} \mathrm{C}\right)$ & $10.3\left({ }^{\circ} \mathrm{C}\right)$ & $30\left({ }^{\circ} \mathrm{C}\right)$ \\
\hline \multirow[t]{2}{*}{ Water } & 0.1 & 1.000 & 0.779 & 0.488 & & & \\
\hline & 50 & 0.938 & 0.755 & 0.500 & $-12.8 \times 10^{-4}$ & $-6.26 \times 10^{-4}$ & $4.86 \times 10^{-4}$ \\
\hline \multirow[t]{2}{*}{ Isopropanol } & 0.1 & & 1.000 & & & & \\
\hline & 100 & & 2.203 & & & $7.90 \times 10^{-3}$ & \\
\hline \multirow[t]{2}{*}{ CCL4 } & 0.1 & & 1.000 & & & & \\
\hline & 100 & & 2.244 & & & $8.08 \times 10^{-3}$ & \\
\hline
\end{tabular}

on the results of Bridgman ${ }^{16}$ and Frost, Werner, and Delgado, ${ }^{17}$ the viscosity for water in the present pressure range can be approximately regarded as constant. In our experiments, we also observed that $C^{*}$ for water varies very slightly with pressure.

In summary, we combine the wall slip and the viscositypressure relationship to obtain the revised theoretical flow rate and the revised normalized friction coefficient as follows:

$$
\begin{aligned}
& Q_{\mathrm{HP}-\text { slip }-p \mu}=Q_{\mathrm{HP}} \cdot\left(1+\frac{8 \delta}{d}-\frac{\alpha \cdot P}{2}\right), \\
& C_{\mathrm{HP} \text {-slip- } p \mu}^{*}=C^{*} \cdot\left(1+\frac{8 \delta}{d}-\frac{\alpha \cdot P}{2}\right) .
\end{aligned}
$$

Two revised results of $10 \mu \mathrm{m}$ for isopropanol and carbon tetrachloride are shown in Figs. 9 and 10. It can be seen that the experimental data agree well with the theoretical prediction. For $d=5 \mu \mathrm{m}$ and $3 \mu \mathrm{m}$ microtubes, similar tendencies are observed, but, owing to the large uncertainty in measuring the diameter, the agreement between the test data and the theoretical predictions are not so convincing, therefore, the related plots are not given here.

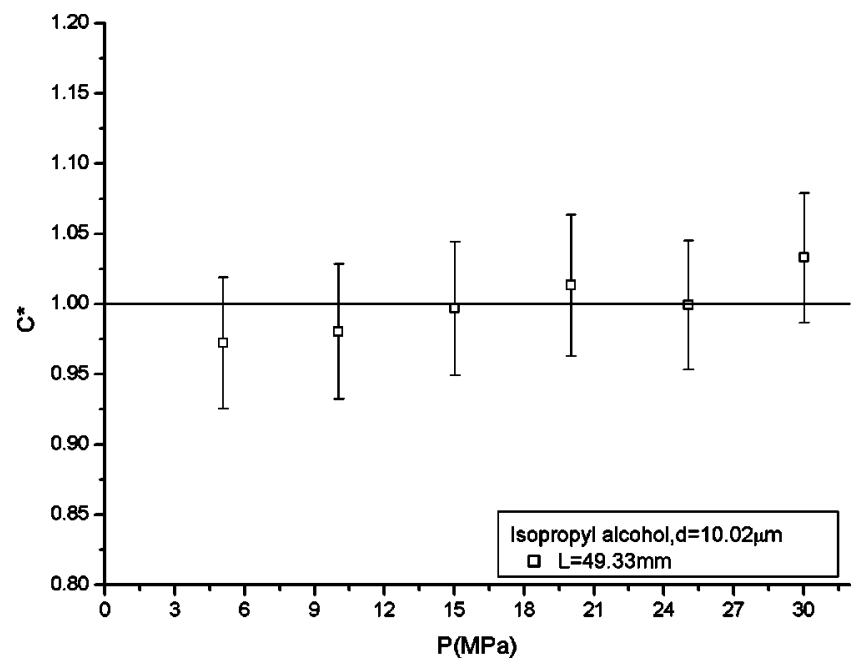

FIG. 9. The revised normalized friction coefficient as a function of pressure for isopropanol in $10 \mu \mathrm{m}$ microtube.

\section{CONCLUSIONS}

The experiments about the flow behavior in 3-10 $\mu \mathrm{m}$ microtubes using di-water and the other two small molecules liquids, isopropanol and carbon tetrachloride, are described in this paper. The experimental results indicate the following.

(a) The flow behavior of isopropanol and carbon tetrachloride in $10 \mu \mathrm{m}$ microtubes under high pressure deviates from the classical HP law, while water does not show the similar phenomenon.

(b) For the isopropanol and carbon tetrachloride, the normalized friction coefficient $C^{*}$ increases with the pressure. But, for water, the variation of $C^{*}$ is very slight with the pressure. The experimental flow rate for water is a little larger than the prediction of HP theory. But for isopropanol and carbon tetrachloride, the experimental flow rate is smaller than the theoretical values under most pressure value $(P \geqslant 10 \mathrm{MPa})$.

(c) A revised HP equation combined with an exponential function of viscosity vs pressure and wall slip is introduced to counteract the difference between experimental and theoretical values. The revised theoretical values are in agreement with the experimental results.

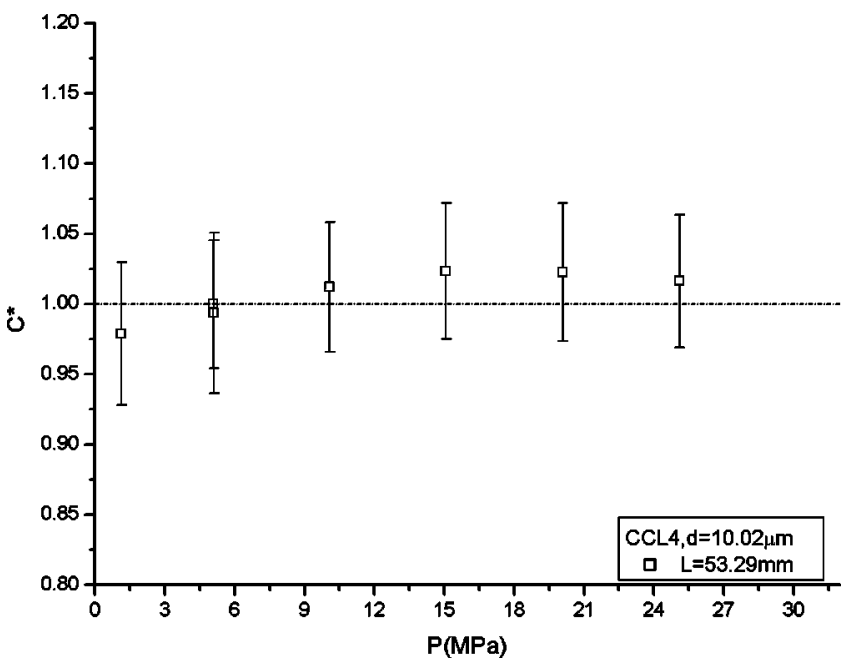

FIG. 10. The revised normalized friction coefficient as a function of pressure for carbon tetrachloride in $10 \mu \mathrm{m}$ microtube. 
For $d=5 \mu \mathrm{m}$ and $3 \mu \mathrm{m}$ microtubes, similar tendencies are observed. However, the agreement between the test data and the theoretical predictions are not so convincing until the smaller uncertainty in measuring the diameter is obtained in the future.

\section{ACKNOWLEDGMENTS}

The authors express their heartfelt thanks to academician Zhe-min Zheng and Professor Guo-can Ling for their kind discussions. Thanks are also due to National Foundation Research Item (G1999033106) and Chinese Academy of Sciences Major Innovation Project (KJCX2-SW-L2) and National Natural Science Foundation of China (10272107) for their support to this research.

${ }^{1}$ C. M. Ho and Y. C. Tai, "Micro-electro-mechanical-systems (MEMS) and fluid flows, " Annu. Rev. Fluid Mech. 30, 579 (1998).

${ }^{2}$ M. Gad-el-Hak, Handbook of MEMS (CRC Press, Boca Raton, 2001).

${ }^{3}$ X. N. Jiang, Z. Y. Zhou, J. Yao, Y. Li, and X. Y. Ye, "Micro-fluid flow in microchannel," Transducers'95, EurosensorsIX, Sweden, June, 317 (1995).

${ }^{4}$ S. M. Flockhart and R. S. Dhariwal, "Experimental and numerical investigation into the flow characteristics of channels etched in $\langle 100\rangle$ silicon," ASME Trans. J. Fluids Eng. 120, 291 (1998).

${ }^{5}$ G. M. Mala and D. Q. Li, "Flow characteristics of water in microtubes," Int. J. Heat Fluid Flow 20, 142 (1999).

${ }^{6}$ M. Makihara, K. Sasakura, and A. Nagayama, "Flow of liquids in micro- capillary tube consideration to application of the Navier-Stokes equations," J. Soc. Precis. Eng. 59, (1993).

${ }^{7}$ J. Pfahler, J. Harley, H. Bau, and J. Zemel, "Gas and liquid flow in small channels," Am. Soc. Mech. Eng., Dynam. Syst. Control Division 32, 49 (1991).

${ }^{8}$ I. Papautsky, J. Brazzle, T. Ameel, and A. B. Frazier, "Laminar fluid behavior in microchannels using micropolar fluid theory," Sens. Actuators, A 73, 101 (1999).

${ }^{9}$ K. V. Sharp, R. J. Adrian, J. G. Santiago, and J. I. Molho, "Liquid flows in microchannels," Handbook of MEMS (CRC Press, Boca Raton, 2001).

${ }^{10}$ Z. H. Li, X. B. Zhou, and S. N. Zhu, "Flow characteristics of non-polar organic with small molecules in a microchannel," Acta Mech. Sin. 3, 432 (2002).

${ }^{11}$ Z. H. Li and H. H. Cui, "Proceeding of experiments about liquid flow through micro-tubes," Int. J. Nonlinear Sci. Num. Simulation 3-4, 577 (2002).

${ }^{12}$ L. D. Landau and E. M. Lifshitz, Theory of Elasticity (Pergamon, New York, 1986)

${ }^{13}$ S. Iida, Constant Table of Physics (in Chinese) (Science Press, Beijing, 1987).

${ }^{14}$ C.-H. Choi, K. Johan, and A. Westin, "To slip or not to slip-Water flows in hydrophilic and hydrophobic micro channel," IMECE2002-33707 (2002).

${ }^{15}$ L. D. Landau and E. M. Lifshitz, Fluid Mechanics (Pergamon, New York, 1987).

${ }^{16}$ P. W. Bridgman, The Physics of High Pressure (G. Bell and Sons, London, 1949).

${ }^{17}$ P. Frost, F. Werner, and A. Delgado, "The viscosity of water at high pressures-especially at subzero degrees centigrade," Rheol. Acta 39, 566 (2000). 